\title{
Experimental and numerical study on laser keyhole welding of 42CrMo under air and argon atmosphere
}

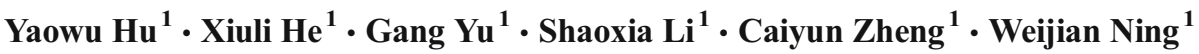

Received: 5 August 2016/Accepted: 31 October 2016/Published online: 10 November 2016

(C) Springer-Verlag London 2016

\begin{abstract}
Laser keyhole welding of $42 \mathrm{CrMo}$ in air and argon atmospheres has been studied both experimentally and numerically. Significant macroscale difference is observed for welding carried out under argon and air shielding. Fusion zone of welding under argon shielding has a " $\nabla$ " shape, while it has a "U" shape for welding in air. The surface of the weldment is smoother for welding in argon when compared with that in air. Oxygen effect is proposed to account for the experimental results. A three-dimensional heat transfer model with a predefined keyhole is developed to study the heat transport and fluid flow in laser welding process. The variation of weld pool geometry and temperature history is investigated for different oxygen concentrations. It is found that a small amount of oxygen could significantly modify the weld pool dimension, while keeping the temperature history of materials, and thus the microstructure, in the fusion zone and heat-affected zone unchanged.
\end{abstract}

Keywords Laser welding · Keyhole welding · Shielding gas · Fluid flow

Yaowu $\mathrm{Hu}$

yaowuhu@gmail.com

Xiuli $\mathrm{He}$

xlhe@imech.ac.cn

Gang Yu

gyu@imech.ac.cn

1 Key Laboratory of Mechanics in Advanced Manufacturing, Institute of Mechanics, Chinese Academy of Sciences, Beijing 100190, People's Republic of China

\section{Introduction}

Shaft and gear are key components of a product, and their quality has critical influence on the service life. The $42 \mathrm{CrMo}$ medium carbon steel has good balance of strength, toughness, and wear resistance and is widely used in automotive crankshafts, gear, and spindles. Because of its high carbon and alloy element content, the weldability is poor. At present, the welding methods are mainly electronic beam welding and friction welding. Vacuum condition is needed, and harmful $\mathrm{X}$-ray is produced in electronic beam welding, which severely restricts its application. For friction welding, the low efficiency and welding defects are concerning. Alternatively, highpower-density laser has attracted enormous research interest and found its wide application in a broad branch of manufacturing areas including selective laser sintering and three-dimensional printing [1-6], surface nanostructuring [7-12], multimaterial joining and integration [13-17], material removal $[18,19]$, and mechanical/optical property enhancements [20-23]. Characteristics, such as contact-free processing, good flexibility and tunablity, high efficiency, and throughput, make laser a feasible route for welding of 42CrMo [24, 25]. Compared with conventional fusion welding process, laser welding has the advantage of high welding speed, narrow heat-affected zone, low distortion, and ease of automation.

The performance of laser welding is largely influenced by the heat and mass transport during the process. Fluid dynamics in the laser-induced weld pool has been considered to be the important mechanism for the heat transport [14, 26-30]. Buoyancy effect and Marangoni effect due to temperature variation have been considered to be the driving forces for fluid flow. In previous works, surface tension of the molten metal is typically considered to vary negatively with temperature. Its spatial gradient drives the fluid to flow from a high- 
temperature area to a low-temperature area $[28,31]$. In recent years, surface-active elements have attracted increasing research interest and are identified to significantly influence the surface tension and subsequent fluid flow. Wang et al. [32] studied the influence of sulfur on fluid flow and weld penetration in a stationary gas tungsten arc (GTA) welding process, by modifying the boundary condition in momentum equations. Experimental study of fusion zone shape variation with different sulfur addition was performed by Mishra et al. [33]. It was found that fusion zone shifts toward the low sulfur side for butt welding of two steel plates with different sulfur concentration. The asymmetric fusion zone profile was understood to result from complex fluid flow in the weld pool. Surface tension of stainless steel with small amount of sulfur increases with temperature initially and starts to decrease when the temperature exceeds a critical value, resulting in complex Marangoni convections in the pool. Besides sulfur, oxygen is also found to be an active element. Oxide particles [34,35], such as $\mathrm{SiO}_{2}, \mathrm{TiO}_{2}$, and $\mathrm{Al}_{2} \mathrm{O}_{3}$, and oxygen in shielding gas were found to influence surface tensions. $\mathrm{Lu} \mathrm{[36]} \mathrm{systematically} \mathrm{studied} \mathrm{weld} \mathrm{pool}$ shape in GTA welding with different oxygen content in the argon shielding gas. It was found that slight difference of oxygen content $(0.3$ and $0.1 \mathrm{vol} \%)$ in shielding gas introduced significantly different depth/width ratios. Similar results have also been reported by Fujii et al. [37] that a reversed Marangoni convection occurred as small amount of $\mathrm{O}_{2}$ or $\mathrm{CO}_{2}$ was added into He shielding gas in TIG welding.

Although many results have been reported for oxygen effect in low-energy-density welding process, few have touched that in high-energy-density laser welding [38-40], especially in the keyhole mode welding. As the most commonly encountered welding atmosphere, air and argon are used as welding atmosphere and compared in the present study. A three-dimensional heat transfer model with oxygen-induced tunable surface tension is developed to quantitatively study the fluid flow and heat transport in the presence of surface-active elements during laser keyhole welding of $42 \mathrm{CrMo}$. The investigation on this subject provides understanding of laser keyhole welding under different shielding gases, the effect of surface-active elements on heat and mass transport in high-temperature Marangoni convection, and could be used as a guidance penetration-controlled remote laser keyhole welding processes.

\section{Experimental}

A set of experiments with two different gas environments and laser scanning speeds were designed and carried out. Rolled alloy steel $42 \mathrm{CrMo}$ with dimension of $40 \times 40 \times 3 \mathrm{~mm}^{3}$ was used in this study. The chemical composition of $42 \mathrm{CrMo}$ sheet is given in Table 1. Oxide layer and contamination were removed from the surface of metal before welding. The surface was polished with no. 200 emery papers and then cleaned with acetone.
Experiments were conducted on a 1-kW Nd:YAG laser material processing system with five-axis $\mathrm{CNC}$ working station. Figure 1 shows the experimental setup. Laser power of $400 \mathrm{~W}$ was used, and the scanning speed varied from 4 to $30 \mathrm{~mm} / \mathrm{s}$. The gas flow rate was $2.5 \mathrm{~L} / \mathrm{min}$, and the relative humidity was $20 \%$. Metallographic samples were prepared by wire cutting, mechanical milling and grinding, and mechanical polishing procedure. The samples were then etched using a solution of $5 \% \mathrm{HNO}_{3}$ in alcohol. Microstructure of the welding seam was characterized by NephotII optical microscopy (OM). Microhardness along the transverse direction of the welded seam was measured by an automatic microhardness tester (HXD-1000B) with a test load of $0.98 \mathrm{~N}$ and a dwelling time of $15 \mathrm{~s}$.

\section{Numerical modeling}

\subsection{Major assumptions}

In this work, the following assumptions are used to study the heat transport and fluid flow in laser welding:

1. The liquid flow is assumed to be incompressible, Newtonian, and laminar.

2. The density change due to the temperature variation is accounted for by the Boussinesq's approximation.

3. The temperature of the molten material at the outer edge of the keyhole is equal to the boiling temperature of the welded material. A keyhole shape of cylindrical form has been proposed.

4. The top surface of the weld pool, except the keyhole area, is considered to be flat.

\subsection{Governing equations}

In general, the governing equations are written with respect to a three-dimensional Cartesian coordinate system in which the specimen is thought to be moving with constant velocity.

Conservation of mass $(i=1,2,3)$,

$\frac{\partial \rho}{\partial t}+\frac{\partial\left(\rho u_{i}\right)}{\partial x_{i}}=0$

where $\rho$ is the fluid density, $u$ is the relative velocity of liquid and solid, $t$ is the time, and $x$ is the spatial coordinate.

Conservation of momentum,

$\frac{\partial\left(\rho u_{i}\right)}{\partial t}+\frac{\partial\left(\rho u_{i} u_{j}\right)}{\partial x_{i}}=\frac{\partial}{\partial x_{i}}\left(\mu \frac{\partial u_{j}}{\partial x_{i}}\right)+S_{u i}$

where $\mu$ is the dynamic viscosity of the liquid phase and $S$ is the source term. 
Table 1 Chemical composition of $42 \mathrm{CrMo}$ (wt $\%$ )

\begin{tabular}{llllllll}
\hline $\mathrm{C}$ & $\mathrm{Cr}$ & $\mathrm{Mo}$ & $\mathrm{Mn}$ & $\mathrm{Si}$ & $\mathrm{P}$ & $\mathrm{S}$ & $\mathrm{Fe}$ \\
\hline $0.38-0.45$ & $0.90-1.20$ & $0.15-0.25$ & $0.50-0.80$ & $0.20-0.40$ & $\leq 0.040$ & $\leq 0.040$ & Bal. \\
\hline
\end{tabular}

Conservation of thermal energy,

$\frac{\partial(\rho c T)}{\partial t}+\frac{\partial\left(u_{i} \rho c T\right)}{\partial x_{i}}=\frac{\partial}{\partial x_{i}}\left(K \frac{\partial T}{\partial x_{i}}\right)+S_{T}$

where $c$ is the heat capacity, $T$ is the temperature, and $K$ is the thermal conductivity.

The source terms are given by,

$$
\begin{aligned}
S_{T} & =-\frac{\partial(\rho \Delta H)}{\partial t}-\frac{\partial\left(\rho u_{i} \Delta H\right)}{\partial x_{i}}-V_{\mathrm{scan}} \frac{\partial(\rho c T)}{\partial x_{1}}-V_{\mathrm{scan}} \frac{\partial(\rho \Delta H)}{\partial x_{1}} \\
S_{u i} & =-\frac{\partial p}{\partial x_{i}}+\frac{\partial}{\partial x_{j}}\left(\mu \frac{\partial u_{j}}{\partial x_{i}}\right)-K_{0} \frac{\left(1-f_{l}\right)^{2}}{f_{l}^{3}+B} u_{i} \\
& +\rho g_{i} \beta_{T}\left(T-T_{\mathrm{ref}}\right)-V_{\mathrm{scan}} \delta_{1 i} \frac{\partial\left(\rho u_{i}\right)}{\partial x_{i}}-V_{\mathrm{scan}} \frac{\partial\left(\rho u_{i}\right)}{\partial x_{1}}
\end{aligned}
$$

where $V_{\text {scan }}$ is the scanning velocity of laser beam, $P$ is the pressure, and $\Delta H$ is the latent enthalpy to account for phase change. $K_{0}$ is a constant representing the mushy zone morphology. $\beta_{T}$ is the coefficient of volumetric expansion due to temperature. $f_{l}$ is the liquid mass fraction. The relative velocity of liquid inside the keyhole is set to zero. $B$ is the small positive constant to avoid the division by zero. $g$ is the gravity acceleration. The first and second term in the right side in Eq. (4) represent the latent heat release and absorption due to phase change at the liquid/solid interface. The remaining two terms result from laser scanning. The third term in the right side in Eq. (5) is a Darcy term, representing the damping force in the mushy zone when fluid is passing through a porous medium. The fourth term accounts for the buoyancy effects caused by temperature variation. The last two terms represent the influence of laser scanning speed on fluid flow of the liquid metal.

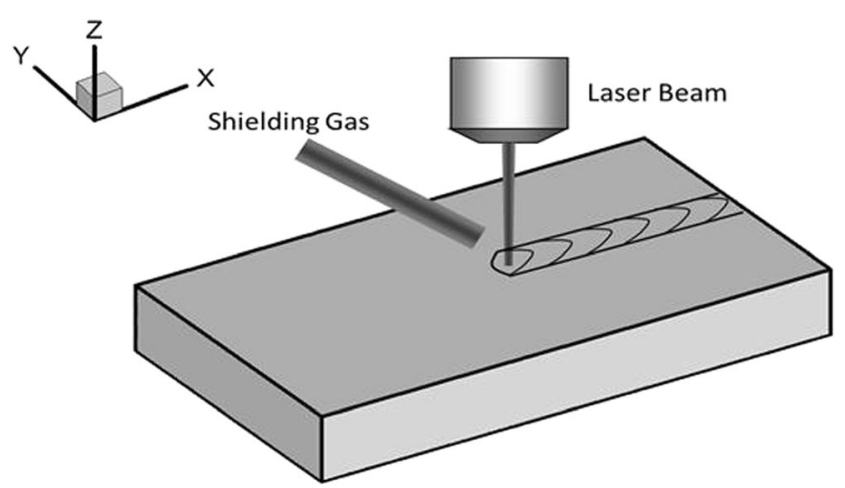

Fig. 1 Schematic diagram of laser welding of $42 \mathrm{CrMo}$
In Eq. (4), $\Delta H$ is given by

$\Delta H=L f_{l}$

where the liquid mass fraction $f_{l}$ is defined as

$f_{l}=\left\{\begin{array}{cc}1 & \text { if } T>T_{1} \\ \frac{T-T_{\mathrm{s}}}{T_{1}-T_{\mathrm{s}}} & \text { if } T_{\mathrm{s}} \leq T \leq T_{1} \\ 0 & \text { if } T<T_{\mathrm{s}}\end{array}\right.$

with $T_{1}$ and $T_{\mathrm{s}}$ being the liquidus and solidus temperature, respectively.

The heat capacity, density, thermal conductivity, and mass diffusion coefficient for the liquid and solid mixture are defined as follows:

$c=f_{\mathrm{s}} c_{\mathrm{S}}+f_{1} c_{1}$

$\rho=f_{\mathrm{s}} \rho_{\mathrm{s}}+f_{1} \rho_{1}$

$K=\left(\frac{g_{\mathrm{s}}}{K_{\mathrm{s}}}+\frac{g_{1}}{K_{1}}\right)^{-1}$

\subsection{Boundary conditions}

At the top surface of the materials, heat loss $\left(Q_{\text {loss }}\right)$ due to convection and radiation is given by

$Q_{\mathrm{loss}}=h_{c}\left(T-T_{a}\right)+\sigma_{b} \varepsilon\left(T^{4}-T_{a}{ }^{4}\right)$

Natural convection is applied to other surfaces of the specimen. During steady state of laser welding, heat input by laser radiation keeps temperature of the molten material at the outer edge of the keyhole to be the boiling temperature.

$T_{\text {keyhole }}=T_{\text {boil }}$

The Marangoni-driven flow at the free surface is described by

$\mu \frac{d u}{d z}=f_{1} \frac{\partial \gamma}{\partial T} \frac{\partial T}{\partial x}$

$\mu \frac{d v}{d z}=f_{1} \frac{\partial \gamma}{\partial T} \frac{\partial T}{\partial y}$

In the solid region,

$u=0, v=0, w=0$ 
Surface tension could be influenced by temperature and surface-active elements. The relationship between surface tension and concentration of surface-active elements in binary metal is studied by Sahoo et al. [41]. The surface tension $\gamma$ is expressed by,

$\gamma=\gamma_{\mathrm{m}}-A\left(T-T_{\mathrm{m}}\right)-R T \Gamma_{\mathrm{s}} \ln \left[1+k_{l} C e^{-\left(\Delta H^{0} / R T\right)}\right]$

where $\gamma_{\mathrm{m}}$ is the surface tension of pure metal at the melting point. $A$ is the negative temperature coefficient of surface tension for pure iron. $\Gamma_{\mathrm{s}}$ is the surface excess at saturation. $R$ is the gas constant; $k_{l}$ is a constant which is related to the entropy of segregation. $\Delta H^{0}$ is the standard heat of adsorption. $C$ is thermodynamic activity.

$$
\begin{aligned}
& \frac{\partial \gamma}{\partial T}=-A-R \Gamma_{\mathrm{s}} \ln \left[1+K_{\mathrm{seg}}\right]+\frac{K_{\mathrm{seg}}}{1+K_{\mathrm{seg}}} \cdot \frac{\Gamma_{\mathrm{s}} \Delta H^{0}}{T} \\
& K_{\text {seg }}=k_{l} C e^{-\left(\frac{\Delta H^{0}}{R T}\right)}
\end{aligned}
$$

The temperature coefficient of surface tension as a function of temperature and oxygen content in $\mathrm{Fe}-\mathrm{O}$ system is shown in Fig. 2. The whole rectangular computational domain is divided into small rectangular control volumes. The governing equations are discretized using the control volume method on a staggered grid. Scalar quantities, such as pressure and temperature, are stored at the center of the computational cell. Velocity components are stored at the corresponding cell face centers. The general framework of the numerical solution rests on the SIMPLEC algorithm. A non-uniform grid of $159 \times 160 \times 50$ meshes is used, with finer grids near the heat source. The minimum grid space is $20 \mu \mathrm{m}$. The mesh grids for numerical simulation are shown in Fig. 3. And the data used for calculations are presented in Table 2 and Fig. 4.

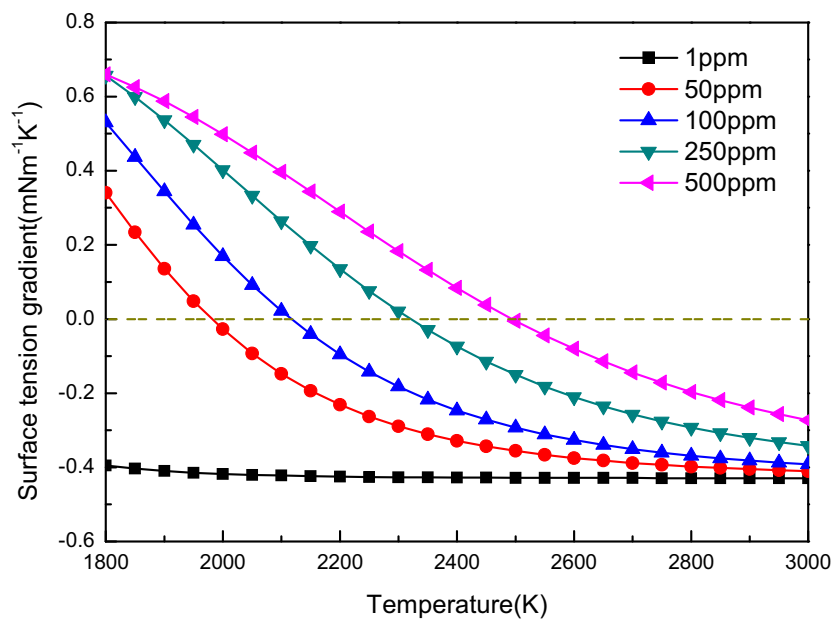

Fig. 2 Temperature coefficient of surface tension as a function of temperature and oxygen concentrations in $\mathrm{Fe}-\mathrm{O}$ system

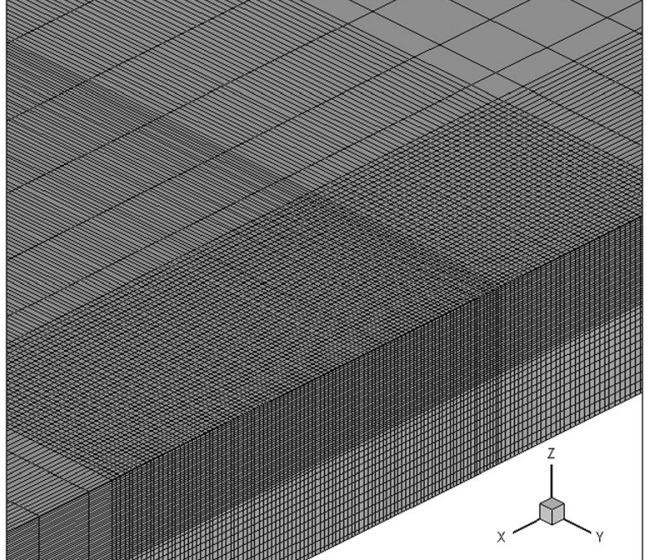

Fig. 3 Mesh grids for numerical simulation

\section{Results and discussions}

If the temperature of the weld pool is higher than the boiling point of the materials, the vaporization occurs. A large surface pressure of vapor generates a keyhole down to a certain depth of the weld. Several important welding characteristics could be observed. Figure 5 shows the weld shapes at different welding speeds under argon and air atmospheres. It is shown that the weld pool obtained under the argon shielding gas has a $\nabla$ shape. The dimension at the top of the cross section of the

Table 2 Material properties used in the simulation

\begin{tabular}{ll}
\hline Property/parameter & Value \\
\hline Density of liquid metal $\left(\mathrm{kg} / \mathrm{m}^{3}\right)$ & 8880 \\
Effective viscosity $\left(\mathrm{kg} / \mathrm{m}^{1} / \mathrm{s}^{1}\right)$ & 0.08 \\
Coefficient of thermal expansion $\left(\mathrm{K}^{-1}\right)$ & $4.50 \times 10^{-5}$ \\
Latent heat $\left(\mathrm{J} / \mathrm{kg}^{1}\right)$ & $2.9 \times 10^{5}$ \\
\hline
\end{tabular}

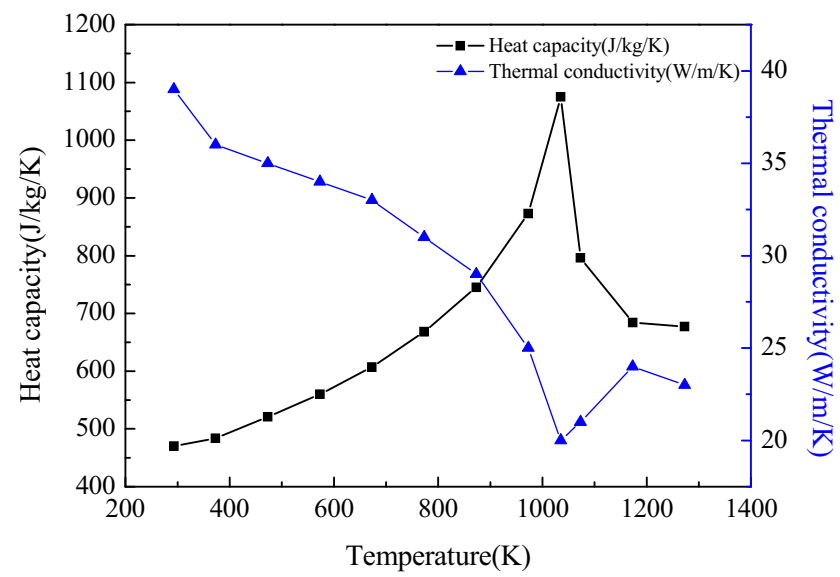

Fig. 4 Material properties used in the simulation 

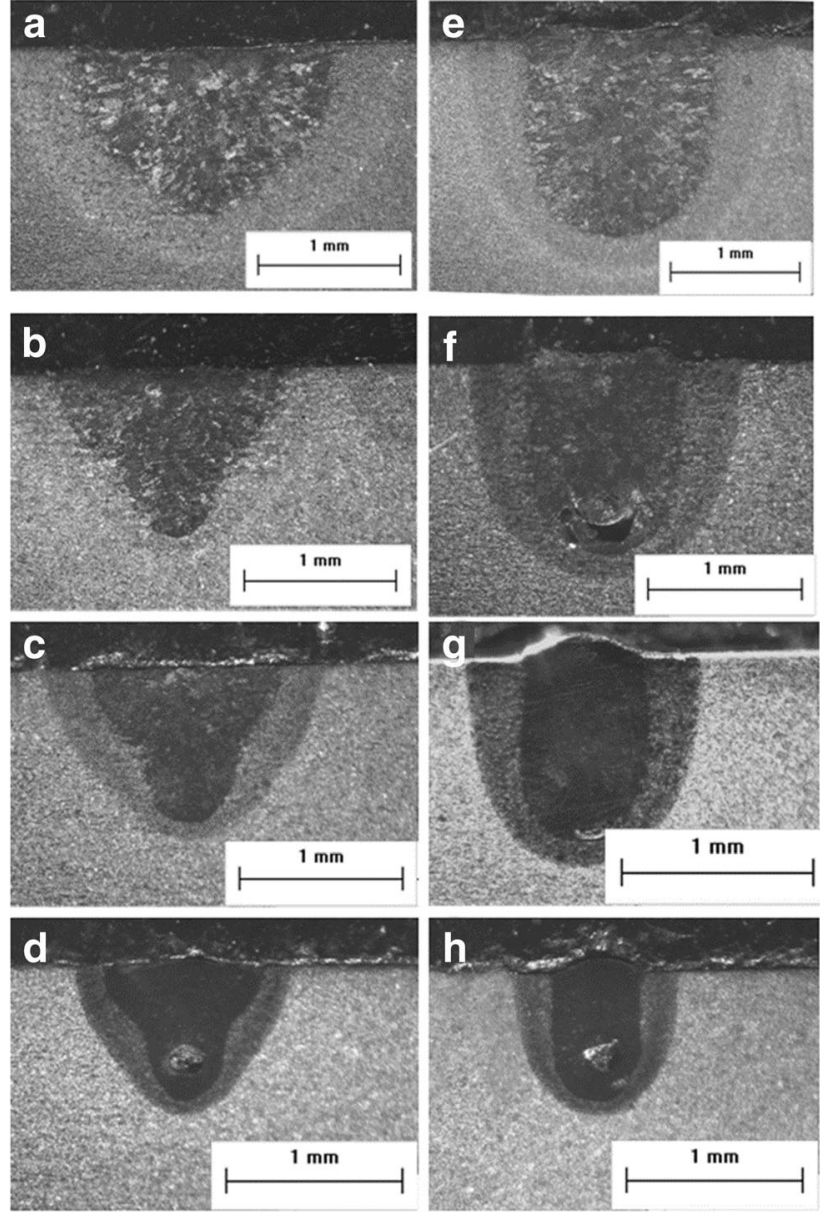

Fig. 5 Weld shapes in argon and air with different welding speed. a Argon, $4 \mathrm{~mm} / \mathrm{s}$; $\mathbf{b}$ argon, $8 \mathrm{~mm} / \mathrm{s}$; $\mathbf{c}$ argon, $15 \mathrm{~mm} / \mathrm{s}$; and $\mathbf{d}$ argon, $30 \mathrm{~mm} / \mathrm{s}$. e Air, $4 \mathrm{~mm} / \mathrm{s} ; \mathbf{f}$ air, $8 \mathrm{~mm} / \mathrm{s} ; \mathbf{g}$ air, $15 \mathrm{~mm} / \mathrm{s}$; and $\mathbf{h}$ air, $30 \mathrm{~mm} / \mathrm{s}$

fusion zone is larger than that at the bottom; on the contrary, the weld pool obtained in air has a U shape. Besides the apparent shape difference, a close analysis of the penetration depth and weld pool width (Fig. 6) indicates significantly different transport phenomena between the two shielding atmospheres. Welds in air have larger penetration depth than those in argon shielding but have smaller weld pool width. For welding speeds between 4 and $15 \mathrm{~mm} / \mathrm{s}$, the difference of weld pool width for two shielding conditions increases as laser scans faster, while the difference of the depth decreases. The aspect ratio (depth/width) is larger than the unity for welding in air and less than the unity in argon shielding. The probability of porosity during welding also differs. Porosity could be found in both argon and air atmospheres when the laser scanning speed is higher than $15 \mathrm{~mm} / \mathrm{s}$, due to increase in solidification rate. For scanning speed between 8 and $15 \mathrm{~mm} /$ $\mathrm{s}$, the sample welded in air is consisted of bubbles, while no porosity is observed for welding in argon. This indicated that porosity is more likely to happen as the welding speed increases, and the probability of porosity when welding in air is much higher than that in argon.

Figure 7 shows the typical surface appearances of the workpieces after laser keyhole welding. Smooth and regular surface ripple patterns could be observed under argon shielding (Fig. 7a). In contrast, the surface ripple patterns for welding in air are irregular, resulting in large surface roughness, as shown in Fig. 7b. Such different surface rippling phenomena can be ascribed to different fluid flow patterns in the weld pool, oxidation of metal in high temperature, and the Kelvin-Helmholtz instability [24] at the interface between the molten layer and the plasma plume.

Although much difference could be observed from the macroscale examination, microstructure and microhardnesses of the weldments under the two conditions are similar. Figure $8 \mathrm{a}-\mathrm{d}$ shows the microstructure of the cross-section zone at different locations. As shown in Fig. 8a, the microstructure of the fusion zone (FZ) is coarse lath martensite. Microhardness test reveals that hardness in the FZ is around $700 \mathrm{HV}$ and has uniform profile with small variations. The material at heat-affected zone (HAZ) near the FZ is shown in Fig. 8b. Due to high cooling rate, this region experiences a

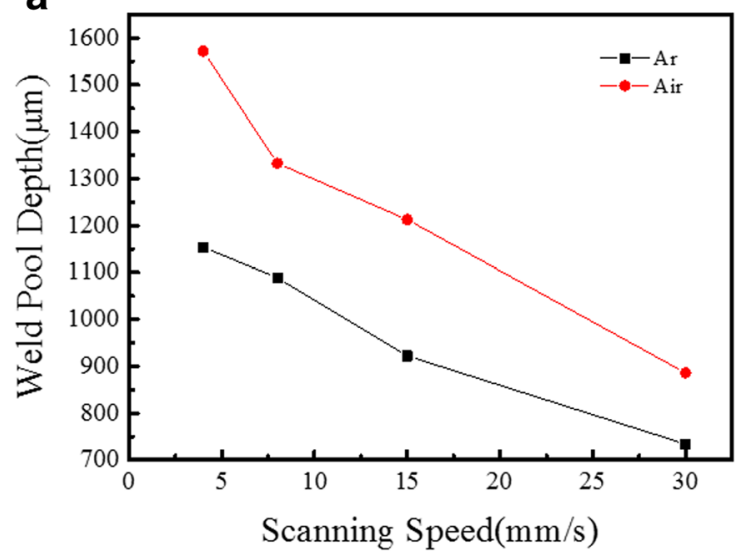

b

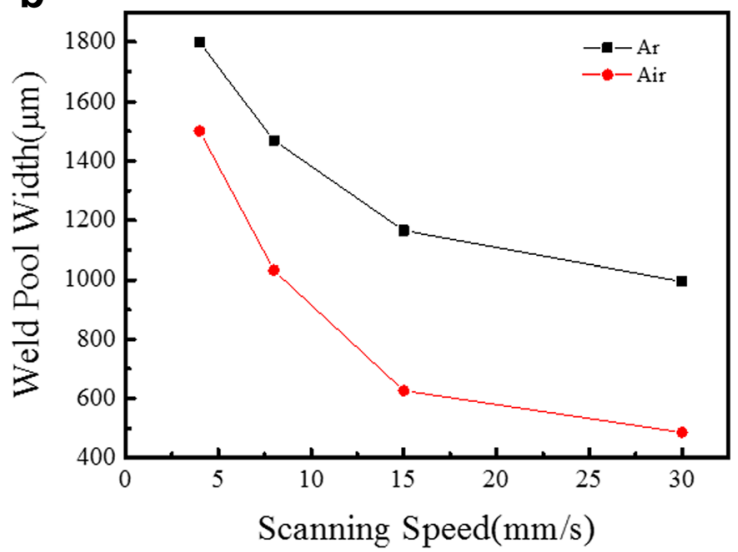

Fig. 6 Variations of weld pool depth (a) and width (b) at different laser scanning speed 
Fig. 7 Surface appearance after welding in argon (a) and in air (b). Scale bar, $1 \mathrm{~mm}$
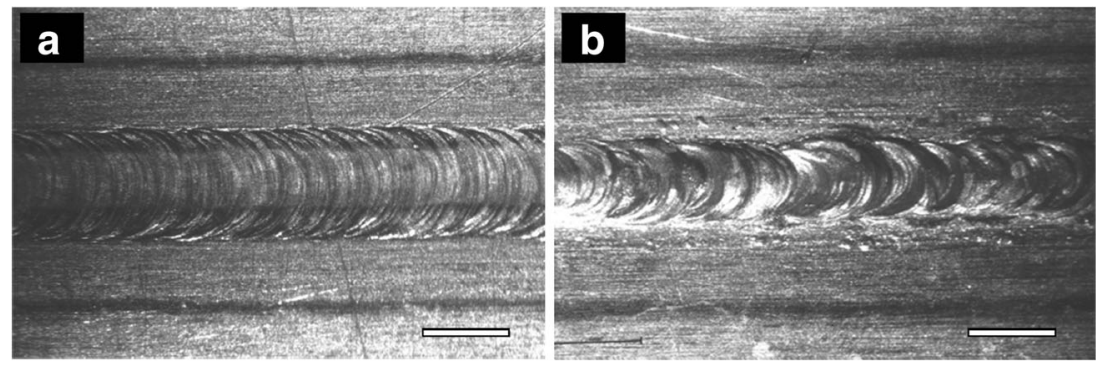

complete quenching process and needle-like martensite is formed at this area. Figure $8 \mathrm{c}$ shows the material in the HAZ away from the FZ. The material in this region is not fully quenched, and mixture structure of matensite, bainite, and untransformed pearlite could be found in this area. Microhardness at HAZ varies from 250 to $700 \mathrm{HV}$. Figure $8 \mathrm{~d}$ shows the OM micrographs of the base metal rolled $42 \mathrm{CrMo}$. It could be seen from the figure that the parent ma- terial is a mixture of ferrite and pearlite. The hardness of this area is measured to be around $250 \mathrm{HV}$.

In order to fully understand the aforementioned differences in weld geometries and appearances, a three-dimensional heat transfer model with molten liquid dynamics is developed to study the heat and mass transport phenomena. The threedimensional temperature fields for the two cases are shown in Fig. 9. It can be seen that temperature fields far away from
Fig. 8 Microstructure of 42CrMo: a fusion zone, b HAZ near FZ, c HAZ far from FZ, and d base metal. Scale bars, $20 \mu \mathrm{m}$
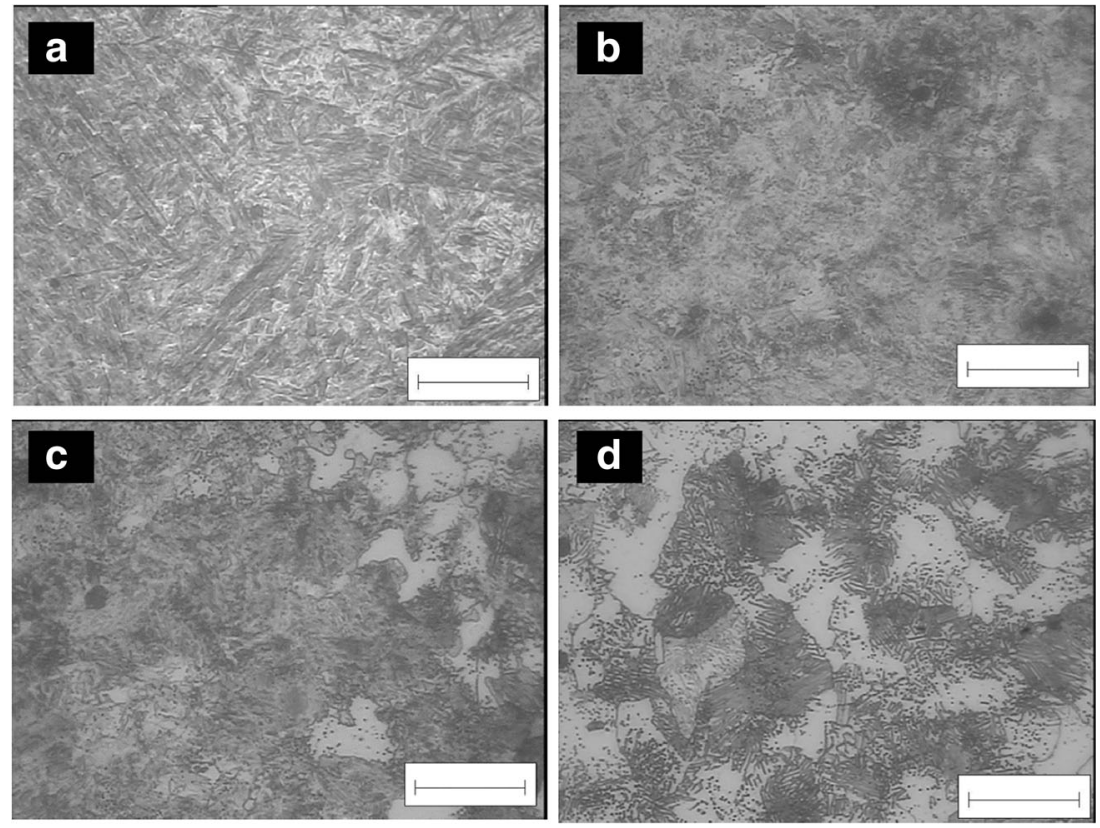

Fig. 9 Three-dimensional view of simulated temperature fields in laser keyhole welding of $42 \mathrm{CrMo}$ under $\operatorname{Ar}(\mathbf{a})$ and air (b). For welding under air atmosphere, oxygen content is set to be $100 \mathrm{ppm}$

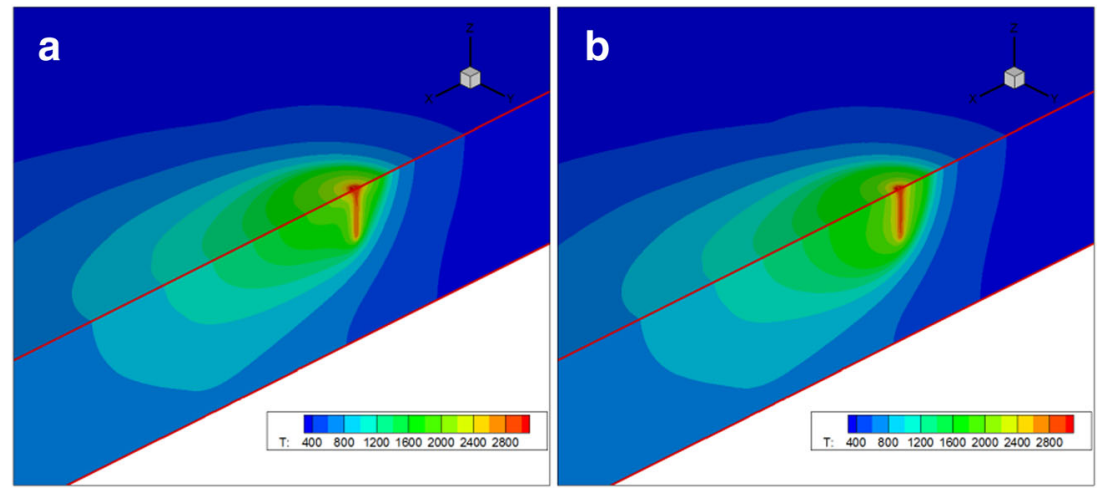


Fig. 10 Calculated temperature fields for welding in argon and air. a Cross section, in argon; $\mathbf{b}$ cross section, in air; $\mathbf{c}$ top view, in argon; and $\mathbf{d}$ top view, in air
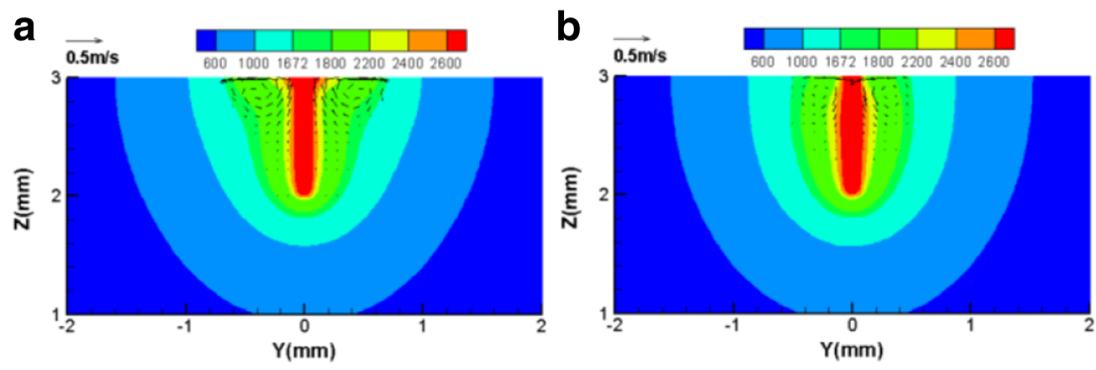

C

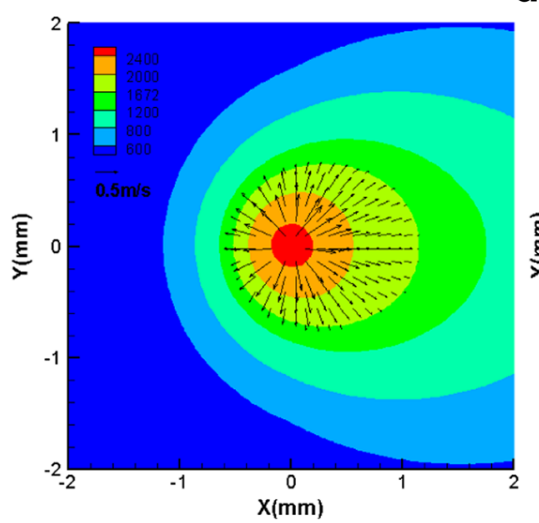

d

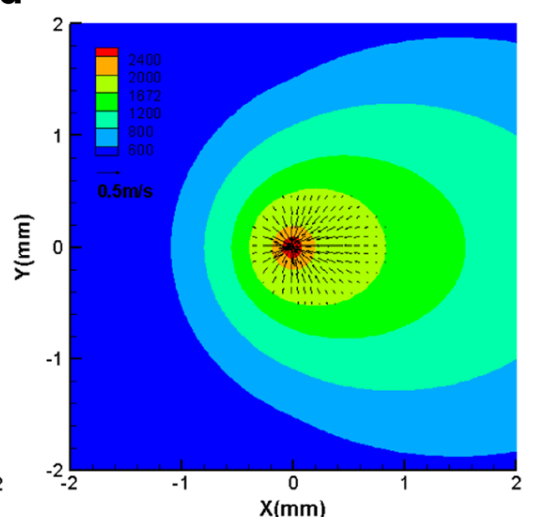

the keyhole are almost identical in two different gas shieldings. The temperature fields along with capillarydriven thermofluid flow at typical cross sections and top
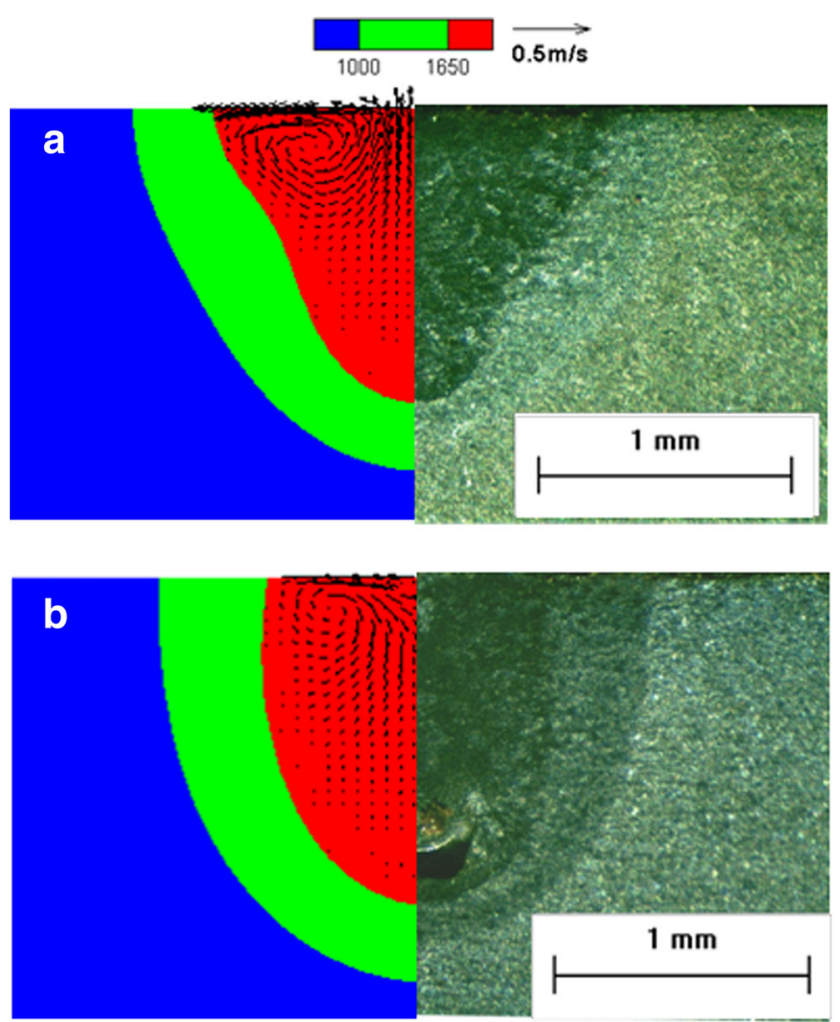

Fig. 11 Comparison of experimental and simulated weld shape: a in argon and $\mathbf{b}$ in air surfaces of the fusion zones are plotted in Fig. 10. Two symmetric vortexes are formed at the upper region of the weld pool in both air and argon atmospheres. The fluids flow at speeds on the order of $0.1 \mathrm{~m} / \mathrm{s}$. Comparing the results obtained from two cases, the vortexes raised from different concentrations of active elements have opposite flow directions, consistent with our recent study on fluid flow in welding of dissimilar couples [29]. The calculated weld pools and HAZs are compared with experimental results, as shown in Fig. 11, demonstrating a good agreement and the validity of our simulation model. Small discrepancy could have resulted from inaccuracy of material properties at high temperatures, differences in geometries and temperature fields of the proposed keyhole and the actual one, keyhole dynamics such as keyhole collapsing, and gas trapping in the weld pool.

The driving force of fluid flow is studied in detail to further shed light on the obtained experimental and simulation differences between two shielding gases. Figure 12 plots the top-surface temperature coefficient of surface tension in air atmosphere. In comparison to a constant value usually used $[14,42,43]$, the temperature coefficient of the surface tension in the present study of air shielding decreases as temperature increases. It reaches a minimum value and becomes negative at the center of the weld pool. Apart from the small region near the weld pool center, the coefficient is positive in other areas. Surfaceactive elements, such as oxygen, could introduce spatially varied coefficients which significantly alter the transport phenomena inside the weld pool. Under argon shielding, the temperature coefficient is negative. The surface 
Fig. 12 Temperature profile and temperature coefficient of surface tension at the top surface $(z=3 \mathrm{~mm}$ in $Y-Z$ plane) for welding in air

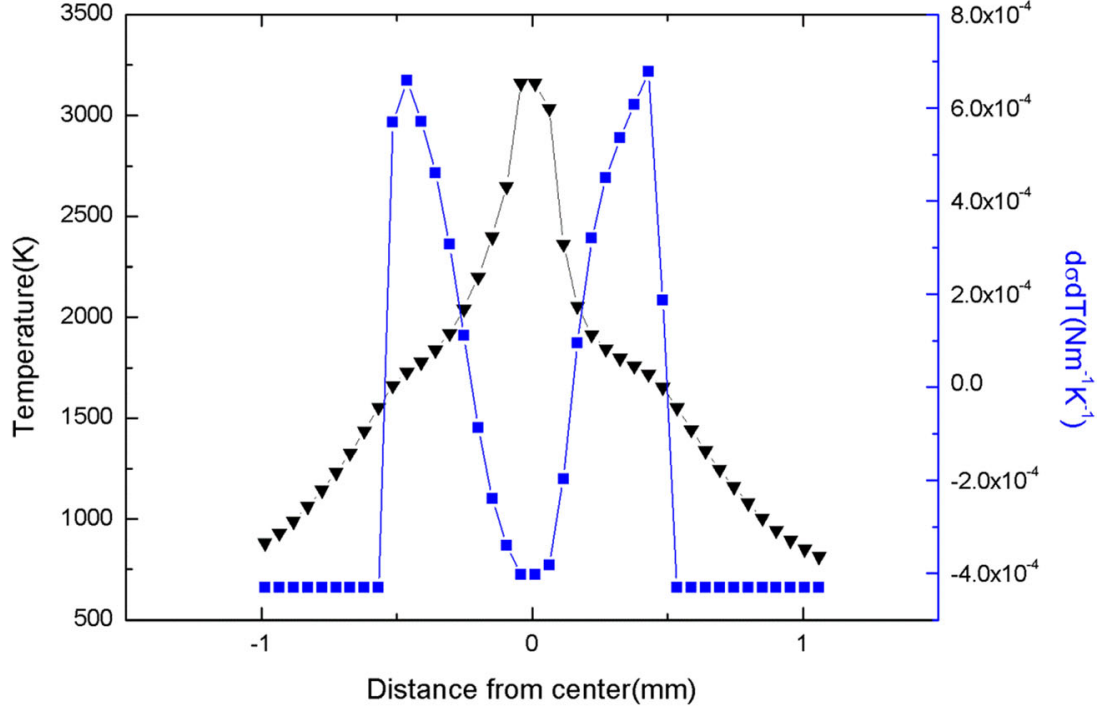

tension at the periphery of the weld pool is larger than that in the center, resulting in fluid flowing from the hot area to the cool area. Heat transport to the periphery is thus enhanced by this outward fluid flow. This increases the weld pool dimension at the top surface, and the fusion zone has a $\nabla$ shape. On the contrary, under air shielding, the metal oxidizes under high temperature, resulting in an increase of oxygen content in the weld pool. Oxygen is then served as a surface-active element and influences the surface tension of the molten metal, thus changing the direction of fluid flow in the weld pool and heat transport. Due to the existence of oxygen, temperature gradients of the surface tension are functions of both temperatures and locations. The material inside of the weld pool has positive values except that at the vicinity of the keyhole. Surface tension varies spatially and is small at the periphery and the center of the weld pool. The molten metal flows from the

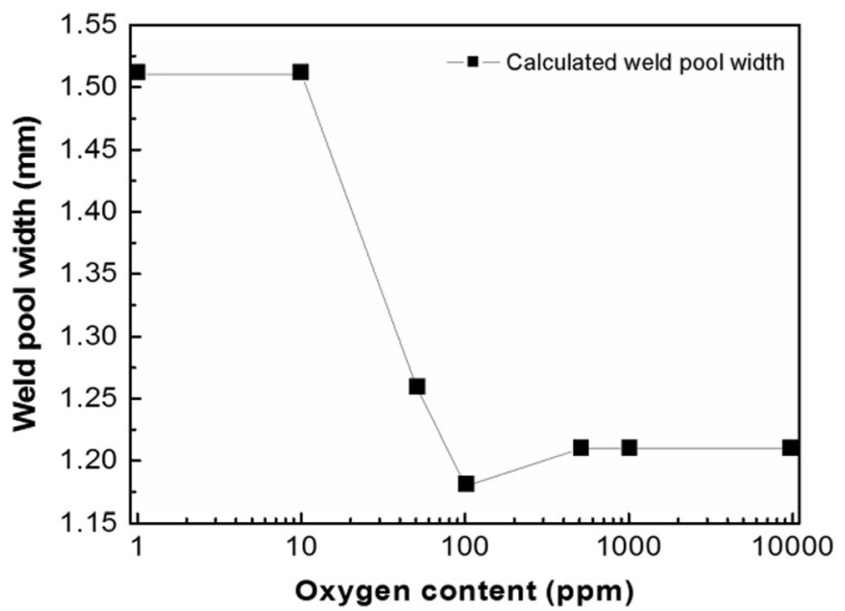

Fig. 13 Calculated weld pool width under different oxygen concentrations periphery to the center of the weld pool where the heat source and the keyhole are located. This hinders the heat transport from the high-temperature regions to the low ones at the top surface, resulting in smaller width of the FZ at the top surface when compared with the case of argon shielding.

In order to study the effect of oxygen systematically, weld pool dimensions are calculated by changing oxygen concentrations in Eq. 17, as shown in Fig. 13. Although the oxygen level in the molten weld pool is difficult to be measured in real time, the simulation with assumed concentrations could provide an in-depth understanding to the welding process. It is found that a slight increase of oxygen content from 10 to $100 \mathrm{ppm}$ could result in a sharp decrease of the weld pool width, while increasing oxygen content from 100 to $500 \mathrm{ppm}$ only has moderate impact on the weld pool width. Further increase of the content above $500 \mathrm{ppm}$ does not influence the weld pool dimensions. These results could be interpreted by considering the role of fluid flow in the molten pool together with oxygen effect according to Eq. (17). It should be noted that the weld pool dimension depends on the temperature fields at the surface, which are controlled through competing effects between conduction mode and convection mode heat transports. For the convection mode, thermocapillary convection has previously been reported to be more pronounced than the Rayleigh-Benard convection due to variation of density [44]. With the increase of oxygen contents, the temperature coefficient of surface tension increases, resulting in a change of the driving forces for the Marangoni convections. This influences both the strength and the pattern of fluid flow. As heat transfer is supported by fluid flow, the weld pool dimension at the surface decreases when the overall direction of flow changes from outward to inward. 

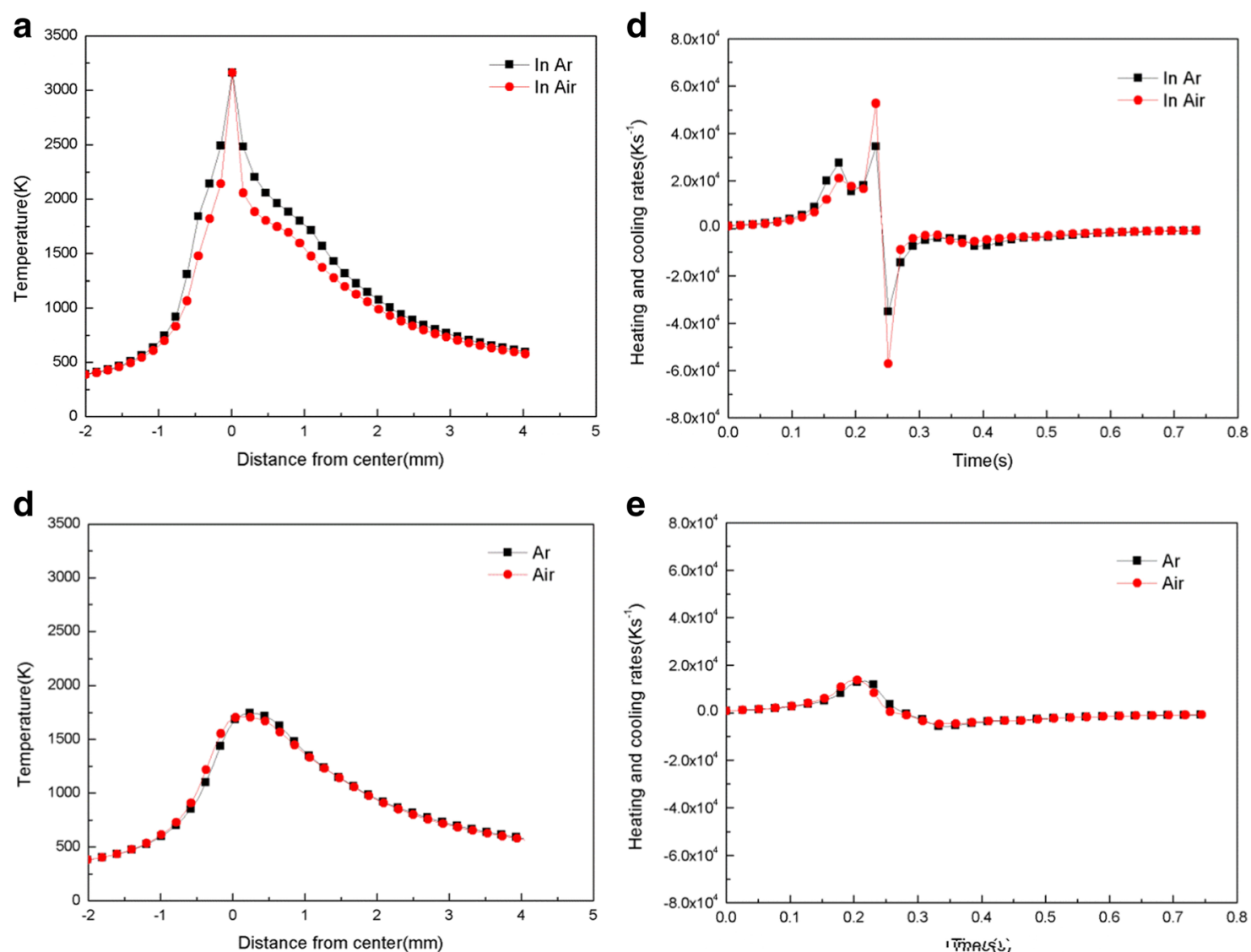

e
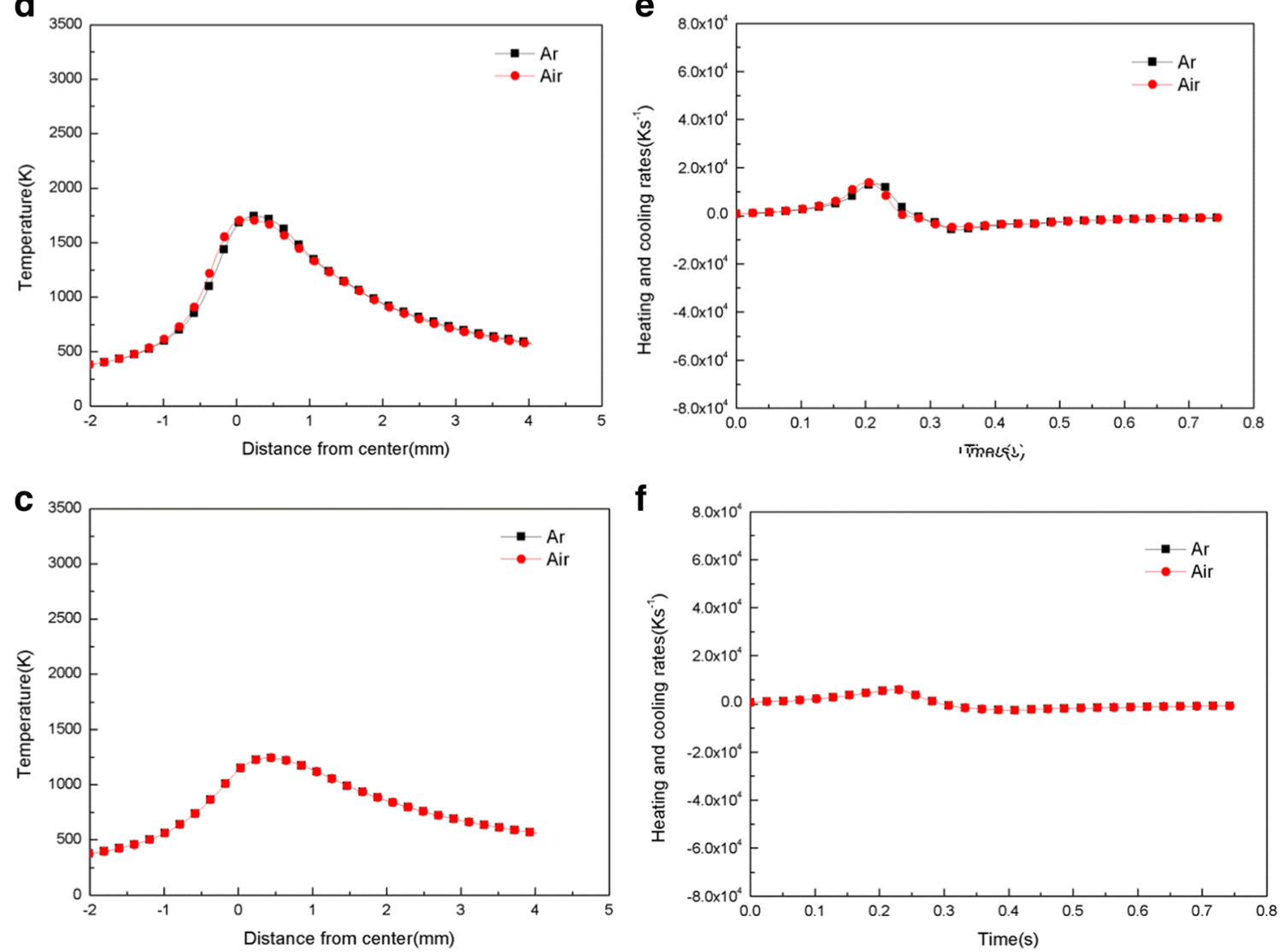

Fig. 14 Temperature profiles along scanning direction inside the keyhole (a), near the weld pool boundary (b), heat-affected zone (c), and their corresponding heating and cooling rates $(\mathbf{d}-\mathbf{f})$

Material temperature histories are then investigated to explain the same microstructures obtained under different conditions. Figure 14 shows the top-surface temperature profiles along the scanning direction, heating and cooling rates at different locations for both cases. The whole heating and cooling processes finish within $1 \mathrm{~s}$. The material inside the keyhole experiences the highest temperature (above $3000 \mathrm{~K}$ ) and heating/cooling rates (above $10^{4} \mathrm{~K} / \mathrm{s}$ ) among all locations considered. Microstructures (coarse lath martensite for FZ and untransformed pearlite for HAZ) vary with locations but are found to be similar for both cases. It is confirmed that the materials inside the weld pool experience the similar temperature histories during the welding process despite of the fact that different shielding gases are used. Hence, similar microstructures are obtained although there is obvious macroscale difference in fusion zone shape for the two shielding gases.

From the above analysis, it is demonstrated that the shape of fusion zone could be controlled by adding small amount of surface-active elements into the process while keeping the desirable microstructure of the weldment 
unchanged. However, the ionization of metal under high temperature, chemical reactions, transient keyhole profile tracking, and possible turbulence in laser keyhole welding are still unresolved problems and provide challenges for future research.

\section{Conclusions}

In this paper, a set of welding process is carried out to investigate laser keyhole welding of $42 \mathrm{CrMo}$ in argon and air gas shielding. Different fusion zones and sample surface morphologies are observed. Oxygen effect is proposed to account for the observed experimental difference. A three-dimensional heat and mass transfer model with surface-active elementdriven thermocapillary flow is developed to study the underlying physical mechanism. The main conclusions are the following:

1. The weld pool obtained under argon gas shielding has a $\nabla$ shape. The dimension at the top of the cross section of the fusion zone is obviously larger than that at the bottom. In comparison, a U shape weld pool is observed under air shielding. Surface ripple pattern is also found to be different. For argon shielding, the surface is smooth, and the ripple pattern is uniform and regular, while rough surface with irregular ripple pattern is observed for air shielding.

2. Oxygen effect on the Marangoni convection inside the weld pool is proposed to account for the experimentally observed difference and similarity. A three-dimensional heat and mass transfer model is developed to analyze fluid flow and temperature fields in laser keyhole welding of $42 \mathrm{CrMo}$ based on an assumed keyhole profile. Surface tension is noticeably affected by oxygen concentration, and the welding process is sensitive to oxygen content in the weld pool. The difference of weld pool width between welding under argon and air shielding results from change of fluid flow pattern from "outward" to "inward" and change of heat transport of laser energy in the weld pool. The influence of oxygen saturates at $500 \mathrm{ppm}$. The calculated results agree well with the experimental ones, indicating the validity of the model.

3. Although there is obvious macroscale difference in fusion zone shape for different gas shielding, the temperature history of material does not change; thus, the microstructure obtained between the two cases is similar. It is proposed that the shape of fusion zone could be tuned by controlled addition of surface-active elements without changing the desirable microstructure of the weldment.

Acknowledgements This work was supported by the National Natural Science Foundation of China under Grant Nos. 11272317 and 11272316.

\section{References}

1. Hribar KC, Meggs K, Liu J, Zhu W, Qu X, Chen S (2015) Threedimensional direct cell patterning in collagen hydrogels with nearinfrared femtosecond laser. Sci Rep 5:17203

2. Bückmann T, Stenger N, Kadic M, Kaschke J, Frölich A, Kennerknecht T, Eberl C, Thiel M, Wegener M (2012) Tailored 3D mechanical metamaterials made by dip-in direct-laser-writing optical lithography. Adv Mater 24:2710-2714

3. Gao W, Singh N, Song L, Liu Z, Reddy ALM, Ci L, Vajtai R, Zhang Q, Wei B, Ajayan PM (2011) Direct laser writing of micro-supercapacitors on hydrated graphite oxide films. Nat Nanotechnol 6:496-500

4. Lin D, Nian Q, Deng B, Jin S, Hu Y, Wang W, Cheng GJ (2014) Three-dimensional printing of complex structures: man made or toward nature? ACS Nano 8:9710-9715

5. Petrochenko PE, Torgersen J, Gruber P, Hicks LA, Zheng J, Kumar G, Narayan RJ, Goering PL, Liska R, Stampfl J, Ovsianikov A (2015) Laser 3D printing with sub-microscale resolution of porous elastomeric scaffolds for supporting human bone stem cells. Adv Healthc Mater 4:739-747

6. Lin D, Richard Liu C, Cheng GJ (2014) Single-layer graphene oxide reinforced metal matrix composites by laser sintering: microstructure and mechanical property enhancement. Acta Mater 80: 183-193

7. Hu Y, Xuan Y, Wang X, Deng B, Saei M, Jin S, Irudayaraj J, Cheng G J (2016) Superplastic forming of metal nanostructure arrays with ultrafine gaps. Adv Mater 1-11

8. Hu Y, Kumar P, Xuan Y, Deng B, Qi M, Cheng G J (2016) Controlled and stabilized light-matter interaction in graphene: plasmonic film with large-scale 10-nm lithography. Adv Opt Mater

9. Vorobyev A. Y, Makin V S, Guo C (2007) Periodic ordering of random surface nanostructures induced by femtosecond laser pulses on metals. J Appl Phys 101

10. Vorobyev AY, Guo C (2008) Colorizing metals with femtosecond laser pulses. Appl Phys Lett 92:3-6

11. Gao H, Hu Y, Xuan Y, Li J, Yang Y, Martinez RV, Li C, Luo J, Qi M, Cheng GJ (2014) Large-scale nanoshaping of ultrasmooth 3D crystalline metallic structures. Science (80- ) 346:1352-1356

12. Hu Y, Kumar P, Xu R, Zhao K, Cheng G J 2015 Ultrafast direct fabrication of flexible substrate-supported designer plasmonic nanoarrays. Nanoscale

13. Keskitalo M, Mäntyjärvi K, Sundqvist J, Powell J, Kaplan AFH (2015) Laser welding of duplex stainless steel with nitrogen as shielding gas. J Mater Process Technol 216:381-384

14. Hu Y, He X, Yu G, Ge Z, Zheng C, Ning W (2012) Heat and mass transfer in laser dissimilar welding of stainless steel and nickel. Appl Surf Sci 258:5914-5922

15. Hu Y, Lee S, Kumar P, Nian Q, Wang W, Irudayaraj J J, Cheng G J (2015) Water flattens graphene wrinkles: laser shock wrapping of graphene onto substrate-supported crystalline plasmonic nanoparticle arrays. Nanoscale

16. Zhao S, Yu G, He X, Hu Y (2012) Microstructural and mechanical characteristics of laser welding of Ti6A14V and lead metal. J Mater Process Technol 212:1520-1527

17. Lee S, Kumar P, Hu Y, Cheng G J, Irudayaraj J (2015) Graphene laminated gold bipyramids as sensitive detection platforms for antibiotic molecules. Chem Commun

18. Paeng D, Yoo JH, Yeo J, Lee D, Kim E, Ko SH, Grigoropoulos CP (2015) Low-cost facile fabrication of flexible transparent copper electrodes by nanosecond laser ablation. Adv Mater 27:2762-2767

19. Mackenzie DMA, Buron JD, Whelan PR, Jessen BS, Silajdźić A, Pesquera A, Centeno A, Zurutuza A, Bøggild P, Petersen DH (2015) Fabrication of CVD graphene-based devices via laser ablation for wafer-scale characterization. 2D Mater 2:045003 
20. Liao Y, Suslov S, Ye C, Cheng GJ (2012) The mechanisms of thermal engineered laser shock peening for enhanced fatigue performance. Acta Mater 60:4997-5009

21. Ye C, Suslov S, Kim BJ, Stach EA, Cheng GJ (2011) Fatigue performance improvement in AISI 4140 steel by dynamic strain aging and dynamic precipitation during warm laser shock peening. Acta Mater 59:1014-1025

22. Ye C, Suslov S, Fei X, Cheng GJ (2011) Bimodal nanocrystallization of NiTi shape memory alloy by laser shock peening and postdeformation annealing. Acta Mater 59:7219-7227

23. Kumar P, Li J, Nian Q, Hu Y, Cheng G J (2013) Plasmonic tuning of silver nanowires by laser shock induced lateral compression. Nanoscale

24. Liu X-B, Yu G, Pang M, Fan J-W, Wang H-H, Zheng C-Y (2007) Dissimilar autogenous full penetration welding of superalloy K418 and $42 \mathrm{CrMo}$ steel by a high power CW Nd:YAG laser. Appl Surf Sci 253:7281-7289

25. Li C, Wang Y, Han B (2011) Microstructure, hardness and stress in melted zone of $42 \mathrm{CrMo}$ steel by wide-band laser surface melting. Opt Lasers Eng 49:530-535

26. Tan W, Shin YC (2015) Multi-scale modeling of solidification and microstructure development in laser keyhole welding process for austenitic stainless steel. Comput Mater Sci 98:446-458

27. Tan W, Shin YC (2014) Analysis of multi-phase interaction and its effects on keyhole dynamics with a multi-physics numerical model. J Phys D Appl Phys 47:345501

28. He X, DebRoy T, Fuerschbach PW (2003) Alloying element vaporization during laser spot welding of stainless steel. J Phys D Appl Phys 36:3079-3088

29. Hu Y, He X, Yu G, Zhao S (2016) Capillary convection in pulsedbutt welding of miscible dissimilar couple. Proc Inst Mech Eng Part C J Mech Eng Sci 1-12

30. Gan Z, Yu G, He X, Li S (2017) Numerical simulation of thermal behavior and multicomponent mass transfer in direct laser deposition of Co-base alloy on steel. Int J Heat Mass Transf 104:28-38

31. Ribic B, Rai R, DebRoy T (2008) Numerical simulation of heat transfer and fluid flow in GTA/laser hybrid welding. Sci Technol Weld Join 13:683-693

32. Wang Y, Shi Q, Tsai HL (2001) Modeling of the effects of surfaceactive elements on flow patterns and weld penetration. Metall Mater Trans B Process Metall Mater Process Sci 32:145-161
33. Mishra S, Lienert TJ, Johnson MQ, DebRoy T (2008) An experimental and theoretical study of gas tungsten arc welding of stainless steel plates with different sulfur concentrations. Acta Mater 56: 2133-2146

34. Xu YL, Dong ZB, Wei YH, Yang CL (2007) Marangoni convection and weld shape variation in A-TIG welding process. Theor Appl Fract Mech 48:178-186

35. Kaul R, Ganesh P, Singh N, Jagdheesh R, Bhagat MS, Kumar H, Tiwari P, Vora HS, Nath AK (2007) Effect of active flux addition on laser welding of austenitic stainless steel. Sci Technol Weld Join 12: $127-137$

36. Lu S (2004) Sensitivity of Marangoni convection and weld shape variations to welding parameters in O2?Ar shielded GTA welding. Scr Mater 51:271-277

37. Fujii H, Sato T, Lu S, Nogi K (2008) Development of an advanced A-TIG (AA-TIG) welding method by control of Marangoni convection. Mater Sci Eng A 495:296-303

38. Zhao CX, Kwakernaak C, Pan Y, Richardson IM, Saldi Z, Kenjeres S, Kleijn CR (2010) The effect of oxygen on transitional Marangoni flow in laser spot welding. Acta Mater 58:6345-6357

39. Zhao CX, van Steijn V, Richardson IM, Kleijn CR, Kenjeres S, Saldi Z (2009) Unsteady interfacial phenomena during inward weld pool flow with an active surface oxide. Sci Technol Weld Join 14: 132-140

40. Naito Y, Mizutani M, Katayama S (2006) Effect of oxygen in ambient atmosphere on penetration characteristics in single yttriumaluminum-garnet laser and hybrid welding. J Laser Appl 18:21

41. Sahoo P, Debroy T, McNallan MJ (1988) Surface tension of binary metal - surface active solute systems under conditions relevant to welding metallurgy. Metall Trans B 19:483-491

42. Mukherjee S, Chakraborty S, Galun R, Estrin Y, Manna I (2010) Transport phenomena in conduction mode laser beam welding of $\mathrm{Fe}-\mathrm{Al}$ dissimilar couple with Ta diffusion barrier. Int J Heat Mass Transf 53:5274-5282

43. Chakraborty N (2009) The effects of turbulence on molten pool transport during melting and solidification processes in continuous conduction mode laser welding of copper-nickel dissimilar couple. Appl Therm Eng 29:3618-3631

44. He X, Fuerschbach PW, DebRoy T (2003) Heat transfer and fluid flow during laser spot welding of 304 stainless steel. J Phys D Appl Phys 36:1388-1398 